\title{
INVESTIMENTO PÚBLICO NA EDUCAÇÃO PRIVADA: OS VOUCHERS COMO INSTRUMENTO DE ALCANCE DA QUALIDADE EDUCACIONAL
}

\author{
Paulo Sergio Bandeira ${ }^{1}$
}

\begin{abstract}
RESUMO: A educação básica é majoritariamente oferecida pelo Estado, mas estaticamente atinge números insatisfatórios nos índices do Pisa e IDEB, retratando a baixa qualidade do ensino e o distanciamento das metas pertinentes. O Estado, para alcançar o padrão de qualidade do ensino e ainda manter o dever constitucional da educação, reconhecendo sua incapacidade de prestação da educação, poderia outorgar às escolas particulares a possibilidade de oferta abrangente desse ensino. Esta pesquisa discorre sobre a alternativa de fomento do Poder Público às escolas particulares através do repasse de crédito, vouchers, que seriam utilizados pelos pais para pagar escolas privadas de melhor qualidade.
\end{abstract}

Palavras chaves: educação; ensino público; ensino privado; voucher; qualidade.

\section{PUBLIC INVESTMENT IN PRIVATE EDUCATION: THE VOUCHERS AS AN INSTRUMENT OF REACH OF EDUCATIONAL QUALITY}

\begin{abstract}
Basic education is mostly provided by the State, but statically reaches a low number in the Pisa and IDEB, depicting the low quality of education and the distancing of relevant targets. The State, in order to reach the quality standard of education and still maintain the constittional duty of education, recognizing its inability to provide education, could give prvate schools the possibility of a comprehensive offer of education. This research deals with the alternative of fomenting the Public Power to private schools through the transfer of credit, vouchers, which would be used to pay for private schools of better quality.
\end{abstract}

Key words: education, public schools, private schools, voucher, quality.

\section{INTRODUÇÃO}

\footnotetext{
${ }^{1}$ Mestrando em Direito Empresarial e Cidadania pelo Centro Universitário Curitiba - UNICURITIBA (20172018). Especialista em Direito Educacional pela Faculdade ITECNE (2017). Especialista em Direito Empresarial pela Universidade Positivo (2013). Graduado em Direito pela Universidade Positivo (2006). Professor do Curso de Pós-graduação em Direito Educacional, módulo Direito Civil Aplicado às Instituições de Ensino, no Grupo Educacional ITECNE. Advogado. Membro da Associação Brasileira de Direito Educacional (ABRADE). Email: paulobandeira@rechadvogados.com.br
} 
O escopo da pesquisa se propõe a trazer questionamentos destinados exclusivamente a alcançar o melhoramento da educação básica (do ensino infantil, formado pelas creches e préescolas, ao ensino fundamental e médio), e a buscar a qualidade da prestação do serviço educacional através da transferência de recursos público às instituições de ensino privadas.

Apresentando dados estatísticos do Programme for International Student Assessment (Pisa) - Programa Internacional de Avaliação de Estudantes -, coordenado pela Organização para Cooperação e Desenvolvimento Econômico (OCDE), bem como do Índice de Desenvolvimento da Educação Básica - IDEB, procura-se demonstrar a inferioridade da qualidade do ensino público comparado ao privado.

Destarte, como opção de melhoramento da qualidade do ensino, este trabalho visa debater a possibilidade da utilização dos vouchers (cupons de crédito), emitidos pelo Poder Público, que poderiam ser utilizados pelos pais ou responsáveis para que pudessem matricular seus filhos na rede escolar privada, sendo tais créditos destinados aqueles que não conseguissem acesso ao ensino público, por falta de vagas, por exemplo, como comumente ocorre na educação infantil, como para aqueles que optassem por escolas privadas reconhecidamente melhores na prestação do serviço educacional, comparativamente às públicas.

O presente artigo não pretende debater as causas da má qualidade do ensino público, muito menos tem por escopo pregar sua extinção. Tem como propósito apenas apontar a superioridade evidente da qualidade do ensino privado, colocando o voucher como uma opção de acesso, especialmente aos mais carentes, a uma educação de qualidade.

Como a pesquisa destina-se à apresentação de alternativa de melhorias do ensino básico e acesso à educação de melhor qualidade, não será tema deste trabalho o debate do Programa Universidade para Todos - PROUNI, haja vista tal programa ser destinado ao ensino superior.

A presente pesquisa, sem o condão de trazer todas as hipóteses de debate sobre o tema, através de uma revisão bibliográfica e dedutiva, faz referência à legislação e a conceitos doutrinários e estatísticos, visando descrever um retrato da educação brasileira e a possibilidade de implementação do voucher como uma alternativa para o alcance da qualidade do ensino.

\section{O RETRATO DA QUALIDADE DO ENSINO PÚBLICO BRASILEIRO}

Não há dúvidas que a educação pública no Brasil está longe de ser a ideal e não atende com qualidade os anseios do povo, notadamente dos mais pobres, que são os maiores 


\section{INVESTIMENTO PÚBLICO NA EDUCAÇÃO PRIVADA: OS VOUCHERS COMO INSTRUMENTO DE ALCANCE DA QUALIDADE EDUCACIONAL}

demandantes desse serviço.

É incontroverso que há necessidade de investimentos em infraestrutura, especialmente para o aumento do número de escolas e maior disponibilização de estudo em tempo integral, cabendo ainda a melhoria de diversos outros fatores, tais como alimentação dos alunos, maior capacitação dos profissionais da educação, majoração dos salários de professores, planejamento de carreiras e fiscalização acentuada na destinação dos recursos destinados à área, de modo a coibir práticas de desvios ilegais de recursos e penalizar fortemente os agentes públicos e privados envolvidos em situações de irregularidades.

Esse retrato lastimável da educação pública não é exclusividade nacional. Diversos países em desenvolvimento também se encontram em quadros semelhantes, especialmente no bloco sul-americano, como Peru e Argentina, embora o Brasil ainda apresente números qualitativos ainda mais baixos que essas nações quando o assunto é a educação.

A má qualidade dos serviços públicos educacionais não é um argumento oriundo do senso comum, encontra lastro em pesquisa empírica série, bastando para tanto observar os números trazidos pelo Programme for International Student Assessment (Pisa) - Programa Internacional de Avaliação de Estudantes - coordenado pela Organização para Cooperação e Desenvolvimento Econômico - OCDE, com participação mundial de 70 países e economias², e no Brasil capitaneado pelo Instituto Nacional de Estudos e Pesquisas Educacionais Anísio Teixeira - INEP (INEP, 2016).

O Pisa se destina a avaliar estudantes matriculados a partir do $8^{\circ}$ ano do ensino fundamental, na faixa etária entre 15 anos e 2 meses e 16 anos e 3 meses, posto ser esse o hiato referencialmente levado em conta na maioria dos países para o término da escolaridade básica. Também são considerados nesse programa questionários preenchidos por diretores e professores que respondem sobre "qualificação, desenvolvimento profissional, práticas de ensino, ambiente para aprendizagem, liderança e gerenciamento escolar” (INEP, 2016).

O escopo do Pisa é produzir indicadores que servirão para melhorar a qualidade da educação no ensino básico. Realizado em diversos países, em escolas públicas (federais, estaduais e municipais) e privadas a cada três anos, com aplicação de avaliações em leitura, matemática e ciências, tendo recentemente, em 2015, ano do último levantamento, sido

\footnotetext{
${ }^{2}$ Hong Kong, Macau, Xangai e Taiwan participaram do Pisa mas não são considerados países pela pesquisa.
} 
incluídas as competências de letramento financeiro e resolução colaborativa de problemas ${ }^{3}$, o programa coleta, além da avaliação propriamente dita das aludidas disciplinas, dados demográficos, socioeconômicos e educacionais, dando uma visão detalhada da qualidade da educação aplicada nas nações avaliadas, possibilitando aos governantes melhorias ou remodelamento de polícias públicas voltadas ao ensino.

Do último resultado do Pisa, com participação de 841 escolas, 23.141 estudantes e 8.287 professores, é que se tem a preocupação com a qualidade da educação quando se dá sua percepção traduzida em números.

Em suma, nas classificações do ranking mundial do Pisa de 2015, considerando-se a média obtida pelas Instituições de Ensino Públicas e Privadas, dentre 70 países avaliados, o Brasil ocupa a $63^{\mathrm{a}}$ posição em ciências, com 401 pontos, a 59 em leitura, com 407 pontos, e a 66 em matemática, com 377 pontos, resultando em uma queda significativa em comparação ao Pisa de 2012, quando o Brasil havia atingido 405 em ciências, 410 em leitura e 391 em matemática, o que demonstra que as políticas públicas voltadas à educação nos últimos anos não surtiram os efeitos esperados.

Todavia, embora vergonhosos, esses números devem ser olhados com mais cautela, analisando-se isoladamente as instituições de ensino públicas (incluindo as escolas federais, estaduais e municipais) das particulares, sendo relevante frisar que o Pisa descreve somente o quadro da educação básica, cuja composição escolar encontra classificação no art. 21, I ${ }^{4}$, da Lei 9394/1966 (Lei de Diretrizes e Bases da Educação Nacional - LDB), portanto, excluída a avaliação do ensino superior.

Do total das 841 escolas avaliadas no país, 738 são públicas, sendo 13 federais, 569 estaduais e 156 municipais, ao passo que apenas 103 instituições são privadas, sendo todas essas instituições sido objeto de aferição de qualidade.

De maneira isolada, as escolas públicas federais obtiveram os melhores índices em ciências, leitura e matemática: respectivamente, 517, 528 e 488 pontos.

Na avaliação das escolas estaduais e municipais, esses números caem vertiginosamente. Em ciências, a rede estadual atingiu 394 pontos e a municipal 329; em leitura, 402 para as escolas dos estados, e 325 pontos para as escolas dos municípios, enquanto em matemática as

\footnotetext{
${ }^{3}$ Esses dados não foram apresentados pela OCDE até o momento da conclusão do relatório final do Pisa.

4 “Art. 21. A educação escolar compõe-se de:

I - educação básica, formada pela educação infantil, ensino fundamental e ensino médio (...)”
} 


\section{INVESTIMENTO PÚBLICO NA EDUCAÇÃO PRIVADA: OS VOUCHERS COMO INSTRUMENTO DE ALCANCE DA QUALIDADE EDUCACIONAL}

instituições de ensino estaduais atingiram a pontuação de 369 e as municipais, 311.

A ressalva feita pelo INEP refere-se à rede municipal, alegando que alunos dessas instituições, mesmo com a idade limite, ainda cursavam o ensino fundamental, de sorte que os demais discentes avaliados já cursavam o ensino médio, o que acabou por impactar nos resultados, haja vista possuírem, em tese, maior conteúdo assimilado, situação possibilitada pelo número superior de anos cursados.

No tocante às instituições de ensino privadas, os resultados foram equivalentes aos das escolas federais, conforme conclusão feita pelo INEP, que as considerou estatisticamente iguais, de modo que as escolas particulares obtiveram em ciências 487 pontos; em leitura, 493 pontos e em matemática, 463 pontos.

Importante frisar que a média dos países da OCDE em ciências e leitura é de 493 pontos, enquanto que, em Matemática, atinge 490 pontos, ou seja, as instituições federais e particulares, quando não superam, aproximam-se dos melhores números mundiais, chamando a atenção, porém, os baixos números obtidos pela esfera estadual e municipal, demonstrando a abissal diferença entre as escolas públicas dos Estados e Municípios comparativamente às privadas.

Nesse particular, o Pisa deve ser analisado juntamente com o último Censo Escolar da Educação Básica (INEP, 2017). Neste relatório é apontando que o país conta com 48,8 milhões de matrículas em 186,1 mil escolas de educação básica; sendo 61,7\% de escolas municipais, cujo número expressivo se deve principalmente pela maior demanda de vagas na educação infantil e fundamental, as quais por sua vez correspondem a 46,8\% das matrículas; a rede estadual detém 16,5\% do número total das instituições de ensino, com 34\% das matrículas; as escolas federais representam apenas $0,4 \%$ dos estabelecimentos de ensino e suas matrículas são inferiores a $1 \%$, enquanto as instituições particulares possuem $21,5 \%$ das escolas, com uma participação nas matrículas de 18,4\%.

A análise conjunta do Pisa e do Censo Escolar demonstra que as escolas federais e particulares, embora em menor número comparativamente às escolas estaduais e municipais, apresentam melhores resultados.

Esses números poderiam ser explicados por inúmeras variantes, não cabendo aqui especificá-las, podendo ser objeto de novas pesquisas. O que se pode afirmar, entretanto, é que indubitavelmente apontam para a péssima qualidade do ensino público [notadamente o estadual e o municipal] e a incapacidade governamental de gerir diretamente a educação no país. 
Dessas premissas, vislumbra-se que as escolas federais, correspondentes a $0,4 \%$ do total das escolas brasileira, ou seja, aproximadamente 744 instituições, demonstram que seu expressivo resultado no Pisa não se deve somente pela aptidão dos alunos - que passam por verdadeiros vestibulares para entrar nessas instituições, algo devido à grande procura - mas também pela capacidade de professores concursados e com planos de carreira, que recebem salários acima daqueles praticados na esfera estadual e municipal, e, principalmente, pela capacidade da União em gerir com mais eficiência um número reduzido de escolas, não se podendo olvidar serem essas instituições de sua exclusiva competência, conforme determina o art. 9, III $^{5}$, e art. 16, I, II e III ${ }^{6}$, da LDB.

As escolas particulares, com pouco mais de 40 mil estabelecimentos, relativos a 21,5\% do total das escolas nacionais, também mostram números elevados no Pisa, resultados que, semelhantemente do que ocorre na esfera federal, são decorrentes de melhores estruturas e maiores investimentos, oriundos, certamente, dos valores recebidos pelas mensalidades escolares pagas pelos pais dos alunos - ou seus responsáveis - e que são reinvestidas nas próprias escolas, sendo certo que muitas delas são administradas por mantenedoras experientes que visam a qualidade do ensino como ferramenta de sobrevivência concorrencial entre as demais escolas privadas.

Disso, vislumbra-se que gerenciamento apurado, somado a investimento pecuniário, resulta em relevantes números de qualidade na educação privada, não se encontrando a mesma receita no ensino público, sobretudo na rede estadual e municipal, devendo-se, portanto, encontrar alternativas de atingimento dessa qualidade para que todos possam acessar um ensino de excelência.

\subsection{OUTRO INDICADOR DA QUALIDADE DO ENSINO NO BRASIL}

Não só o Pisa é utilizado como balizador da qualidade do ensino no Brasil, na medida em que o INEP, desde 2005, através do Índice de Desenvolvimento da Educação Básica - IDEB,

\footnotetext{
5 “Art. $9^{\circ}$ A União incumbir-se-á de:

III - prestar assistência técnica e financeira aos Estados, ao Distrito Federal e aos Municípios para o desenvolvimento de seus sistemas de ensino e o atendimento prioritário à escolaridade obrigatória, exercendo sua função redistributiva e supletiva (...)”

6 “Art. 16. O sistema federal de ensino compreende:

I - as instituições de ensino mantidas pela União;

II - as instituições de educação superior criadas e mantidas pela iniciativa privada;

III - os órgãos federais de educação.”
} 


\section{INVESTIMENTO PÚBLICO NA EDUCAÇÃO PRIVADA: OS VOUCHERS COMO INSTRUMENTO DE ALCANCE DA QUALIDADE EDUCACIONAL}

avalia o ensino fundamental (anos iniciais, da $1^{\mathrm{a}}$ à $4^{\mathrm{a}}$ série, e anos finais, da $5^{\mathrm{a}}$ à $9^{\mathrm{a}}$ série) e médio, aplicando aos alunos da rede estadual, municipal e privada, respectivamente para cada etapa do ensino, a Prova Brasil e o Sistema de Avaliação da Educação Básica - SAEB, nas quais são apuradas as médias das notas obtidas em provas de língua portuguesa e matemática, que, por sua vez são multiplicadas pela média de aprovação/retenção das séries, resultando, então, no aludido índice (INEP, 2015).

Essas avaliações ocorrem a cada 2 anos e servem para mensurar evolução, estagnação ou retração da qualidade do ensino público e privado, ao passo que no Brasil foram estipuladas metas de melhoria do IDEB tomando como base os resultados internos obtidos pelos 20 melhores países integrantes da OCDE.

Nessa avaliação, cada etapa do ensino vem recebendo uma pontuação do IDEB desde 2005. Os resultados foram os seguintes: no ensino fundamental (anos iniciais) pontuação de 3,8; ensino fundamental (anos finais), pontuação de 3,5; e ensino médio, pontuação de 3,4.

Para melhorar esses números, o Governo Federal, com vistas a aumentar a qualidade da educação, estipulou como objetivo, para atingimento em 2021, a pontuação de 6,0 para o ensino fundamental (anos iniciais); de 5,5 para o ensino fundamental (anos finais); e 5,2 para o ensino médio, cujo compromisso encontra-se estampado na meta 7 da Lei 13.005/2014, cuja legislação traça o Plano Nacional de Educação - PNE (MEC, 2014)

Em que pese o citado esforço legislativo, ressalta-se que no ano de 2015, data do último relatório produzido pelo INEP, o IDEB (INEP, 2015) deixou a desejar, alcançando para o ensino fundamental (anos iniciais) o resultado de 5,5 pontos; para o ensino fundamental (anos finais) 4,5; e para o ensino médio a pontuação de 3,7.

Observam-se, não se pode negar, melhorias nos números atuais comparados a 2005, não obstante ainda se encontrem muito distantes das metas estipuladas para o ano de 2021.

Embora tais índices tenham tido uma discreta melhora, o resultado do IDEB causa extrema preocupação, especialmente no ensino médio, posto que se corre o sério risco da meta não ser atingida no tempo programado.

O baixo desempenho projetado por esse índice foi utilizado inclusive como um dos fundamentos da exposição de motivos da polêmica ${ }^{7}$ Medida Provisória 746/2016, convertida

\footnotetext{
${ }^{7}$ Enfrentou resistência de diversos setores, especialmente dos profissionais de educação básica dos estados e municípios, além de diversas contestações quanto ao mérito da Medida Provisória, posto que se levantou a discussão se realmente os elementos de relevância e urgência, essenciais para o uso da MP, segundo o art. 62 da
} 
na Lei 13.415/2017, chamada “Lei de Reforma do Ensino Médio”, que, dentre relevantes modificações, alterou diversos artigos da LDB, relativos, por exemplo, à carga horária anual, aos currículos de disciplinas, à vinculação da Base Nacional Comum Curricular (BNCC) e à classificação dos profissionais da educação.

Assim como no Pisa, o levantamento trazido no IDEB deve ser cotejado com mais verticalidade, principalmente quando se isolam somente os resultados produzidos pelas escolas privadas, sem os quais certamente os números atuais seriam ainda mais pífios se considerados fossem somente os das escolas públicas municipais e estaduais.

Os resultados das instituições particulares foram os seguintes: para o ensino fundamental (anos iniciais), atingiu-se 6,8; para o ensino fundamental (anos finais), atingiu-se 6,1; e, para o ensino médio, atingiu-se 5,3, ou seja, em todas as etapas o ensino privado se mostrou melhor que o ensino público, provando, novamente, que a notoriedade da qualidade do ensino particular não encontra fulcro somente no senso comum, demonstrando-se estatisticamente sua superioridade qualitativa - e isso não pode ser ignorado.

Das análises estatísticas trazidas pelo Pisa e pelo IDEB, surgem dois questionamentos: o Brasil tem capacidade administrativa para adotar um modelo de gestão educacional voltado às escolas estaduais e municipais semelhantes às federais, ou, em admitindo sua ineficiência, reconhece a baixa qualidade educacional pública ao ponto de possibilitar à iniciativa privada, dada a reconhecida superioridade na qualidade, a prestação do serviço para parte da população, remunerando as escolas particulares?

Destarte, buscando sugestões de resposta ao segundo questionamento, sem a pretensão de esgotar o tema, passa-se a tratar da análise da possibilidade da criação de créditos estudantis pagos pelo poder público, nos âmbitos federal, estadual e municipal, às escolas particulares com vistas a alcançar a melhoria da qualidade da educação nacional no que se refere ao ensino básico, podendo essa alternativa ser viabilizada através de vouchers ou documentos similares de representação de créditos.

Não é, por óbvio, escopo desse trabalho defender a ideia de extinção do ensino público da forma como vem sendo oferecido, mas tão somente trazer à baila a discussão de uma opção que deverá ser analisada - e criticada - com a pretensão de melhoramento da qualidade da

Constituição Federal, estariam presentes, não se esquecendo das alegações de que o assunto deveria ter sido mais debatido com a sociedade brasileira, posto tratar-se de matéria ligada à educação. 


\section{INVESTIMENTO PÚBLICO NA EDUCAÇÃO PRIVADA: OS VOUCHERS COMO INSTRUMENTO DE ALCANCE DA QUALIDADE EDUCACIONAL}

educação a todos os brasileiros, oferecendo verdadeiro acesso ao direito social da educação (art. $6^{\circ 8}$ ) com a finalidade de alcançar a plenitude do dever constitucional estampado na carta magna $\left(\right.$ art. $\left.205^{9}\right)$.

\section{O INVESTIMENTO ATRAVÉS DOS VOUCHERS E A BUSCA PELA QUALIDADE EDUCACIONAL}

A educação é dever constitucional do Estado, não se podendo olvidar da mesma obrigação à família, e promovida e incentivada com a colaboração da sociedade, devendo ser obrigatoriamente prestada dentro de padrões de qualidade.

Nesta toada, o investimento público educacional na iniciativa privada pode ser plenamente factível em nosso ordenamento, posto que a persecução do dever educacional, diante de uma análise sistemática constitucional, não pressupõe sua prestação exclusiva e unicamente através do ensino público, de modo que o cumprimento dessa obrigação constitucional do serviço educacional pode, como se verá nesta pesquisa, ter sua qualidade alcançada através da colaboração do ensino privado, possibilitando o acesso a melhores escolas, culminando com a consequente elevação dos índices atualmente críticos do Pisa e IDEB.

A coexistência das instituições públicas e particulares de ensino (art. 206, III ${ }^{10}, \mathrm{CF}$ ), aliada à prévia autorização à iniciativa privada para prestação do ensino, desde que cumpridas as normas gerais de educação nacional e a avaliação de qualidade pelo Poder Público (art. 209, I e $\left.\mathrm{II}^{11}, \mathrm{CF}\right)$, servem como ponto de partida para que o Estado seja autorizado a fomentar o ensino privado, de modo a cumprir seu dever constitucional da educação, alocando verbas públicas com destinação às escolas particulares, principalmente para que sejam ofertadas vagas aos mais carentes em instituições de ensino de reconhecida qualidade. Tal medida cumpriria não só ao atendimento de um direito social, estampado no art. $6^{\circ}$ da Constituição Federal, mas

\footnotetext{
8 “Art. $6^{\text {o }}$ São direitos sociais a educação, a saúde, a alimentação, o trabalho, a moradia, o transporte, o lazer, a segurança, a previdência social, a proteção à maternidade e à infância, a assistência aos desamparados, na forma desta Constituição."

9 “Art. 205. A educação, direito de todos e dever do Estado e da família, será promovida e incentivada com a colaboração da sociedade, visando ao pleno desenvolvimento da pessoa, seu preparo para o exercício da cidadania e sua qualificação para o trabalho.”

10 “Art. 206. O ensino será ministrado com base nos seguintes princípios:

III - pluralismo de ideias e de concepções pedagógicas, e coexistência de instituições públicas e privadas de ensino (...)”

11 “Art. 209. O ensino é livre à iniciativa privada, atendidas as seguintes condições:

I - cumprimento das normas gerais da educação nacional;

II - autorização e avaliação de qualidade pelo Poder Público.”
} 
também alcançaria os objetivos fundamentais da República Federativa do Brasil, construindo uma sociedade justa e solidária, garantindo o desenvolvimento nacional, a erradicação da pobreza e da marginalização, bem como reduziria as desigualdades sociais e propiciaria a promoção do bem de todos (art. $3^{\circ}$, I, II, III e IV $^{12}$ da CF), elementos que poderiam ser conquistados através da educação do povo.

O aprimoramento e o acesso à educação, especialmente voltado ao atendimento dos direitos da criança e do adolescente, é assunto de tamanha relevância que vem sendo discutido internacionalmente desde 1948 com a Declaração Universal dos Direitos Humanos, na qual já se chamava a atenção para esse tema educacional como um dos pilares de desenvolvimento de uma nação.

Disso, seguiram diversos tratados internacionais discorrendo sobre o direito à educação, cabendo aqui mencionar apenas dois: a Convenção Sobre os Direitos da Criança ${ }^{13}$, aprovada pela Organização das Nações Unidas - ONU em 1989, que "acolhe a concepção do desenvolvimento integral da criança, reconhecendo-a como verdadeiro sujeito de direito, a exigir proteção especial e absoluta prioridade” (PIOVESAN, 2013, p. 276), tendo sido internalizado pelo Brasil através do Decreto 99.710/1990, cujos dispositivos trouxeram a preocupação com a obrigatoriedade do ensino fundamental compulsório e o desenvolvimento dos padrões de educação; e o Pacto Internacional dos Direitos Econômicos, Sociais e Culturais, adotado pela ONU em 1966, sendo seu maior objetivo "incorporar os dispositivos da Declaração Universal sob a forma de preceitos juridicamente obrigatórios e vinculantes (PIOVESAN, 2013, p. 251), recepcionado nacionalmente pelo Decreto 591/1992, afirmando, dentre diversas disposições ligadas à educação, a implementação de um sistema adequado de bolsas de estudo ${ }^{14}$ fomentadas pelo Estado.

\footnotetext{
12 “Art. $3^{\circ}$ Constituem objetivos fundamentais da República Federativa do Brasil:

I - construir uma sociedade livre, justa e solidária;

II - garantir o desenvolvimento nacional;

III - erradicar a pobreza e a marginalização e reduzir as desigualdades sociais e regionais;

IV - promover o bem de todos, sem preconceitos de origem, raça, sexo, cor, idade e quaisquer outras formas de discriminação."

13 A Convenção Sobre os Direitos da Criança trouxe o conceito de "proteção integral", que, ao lado de outros relevantes princípios, foi utilizado como supedâneo ao Estatuto da Criança e do Adolescente.

14 "Decreto 591/1992: Art. 13 - Os Estados Partes do presente Pacto reconhecem o direito de toda pessoa à educação. Concordam em que a educação deverá visar ao pleno desenvolvimento da personalidade humana e do sentido de sua dignidade e fortalecer o respeito pelos direitos humanos e liberdades fundamentais. Concordam ainda em que a educação deverá capacitar todas as pessoas a participar efetivamente de uma sociedade livre,
} 


\section{INVESTIMENTO PÚBLICO NA EDUCAÇÃO PRIVADA: OS VOUCHERS COMO INSTRUMENTO DE ALCANCE DA QUALIDADE EDUCACIONAL}

Nota-se que esses tratados internacionais trazem a obrigação do Estado prestar efetivamente a educação, buscando o desenvolvimento de seus cidadãos, empregando meios para que se atinja a finalidade do atendimento educacional de seu povo.

Todavia, as aludidas orientações alienígenas e os dispositivos constitucionais não afirmam que o Estado deverá prestar a educação de forma exclusiva, o que possibilita pensarse em por que não alargar ainda mais a possibilidade de acesso dos estudantes da rede pública à rede privada, haja vista serem estes educando os maiores prejudicados pelo ensino desqualificado que vem sendo prestado pelas escolas estatais, salvo raras ilhas de excelência que existem no país.

Vale dizer, tal afirmação não tem o condão de desmerecer o ensino público ou desprestigiar boas (e poucas) escolas estaduais e municipais que oferecem um serviço educacional qualificado, mas encontra lastro nas conclusões trazidas pelos dados estatísticos do Pisa e igualmente do IDEB, cujos números mostram a qualidade superior da educação privada quando comparada à educação pública.

A educação, na esfera pública ou privada, poderia ser colocada como uma opção dada aos pais para que escolhessem as instituições com melhor índice de qualidade no ensino, retirando do Estado a obrigação pelo gerenciamento dessa atividade e outorgando à iniciativa privada a prestação do serviço educacional. Caberia ao Estado somente regular essa prática e evidentemente adimplir pecuniariamente as instituições de ensino particulares pelos serviços prestados aos alunos advindos do ensino público.

Essa é a ideia inicialmente trazida por Milton Friedman, reconhecido autor liberal e vencedor do prêmio Nobel de Economia, que, analisando o mercado norte americano, pregou em seus trabalhos a possibilidade de escolha dos pais - e não do governo - escolherem as escolas onde seus filhos estudariam, denominando tal atividade como school choice. Com efeito, os serviços educacionais seriam adimplidos através de certificados dados pelo Estado aos genitores através de cupons de crédito, chamados vouchers, e que seriam utilizados para saldar a contrapartida dos serviços escolares privados nas escolas que melhor atendessem suas

favorecer a compreensão, a tolerância e a amizade entre todas as nações e entre todos os grupos raciais, étnicos ou religiosos e promover as atividades das Nações Unidas em prol da manutenção da paz [...]

e) Será preciso prosseguir ativamente o desenvolvimento de uma rede escolar em todos os níveis de ensino, implementar-se um sistema adequado de bolsas de estudo e melhorar continuamente as condições materiais do corpo docente.” 
expectativas.

Nos ensinamentos de Friedman (2014, cap. 6), o conceito é facilmente entendido:

\begin{abstract}
Os governos poderiam exigir um nível mínimo de escolarização financiada, oferecendo aos pais vales resgatáveis por determinada importância, por filho, por ano, para pagar serviços educacionais. Os pais, então, teriam liberdade para gastar essa importância, e qualquer acréscimo que se dispusessem a pagar por conta própria, com a compra de serviços educacionais de instituição "credenciada", de sua própria escolha. Os serviços educacionais poderiam ser prestados por empresas privadas, com fins lucrativos, ou por organizações sem fins lucrativos. O papel do governo se limitaria a garantir que todas as escolas atendessem a certos padrões mínimos, como inclusão de conteúdo comum básico em seus programas, da mesma maneira como hoje inspeciona restaurantes para garantir a observância de certos requisitos mínimos de higiene.
\end{abstract}

Ainda, segundo sua tese, como decorrência desse poder de escolha, as escolas, públicas e particulares, dentro de um critério econômico concorrencial, competiriam entre si pelos alunos, o que fomentaria o aumento da qualidade dos serviços, uma vez que a procura e o interesse por essas instituições visariam sempre aquelas que oferecessem o melhor nível qualitativo educacional.

Vale dizer, o custo unitário do aluno, que atualmente é aplicado diretamente no ensino público, poderia ser utilizado facultativamente pelos pais ou responsáveis na escolha de escolas particulares com índices de qualidade superiores às escolas estatais ou municipais.

A utilização desses vouchers não objetiva ou se destina à extinção da rede pública, posto que aquelas escolas estaduais ou municipais reconhecidamente de qualidade não perderiam seus alunos para instituições privadas, de tal sorte que a concorrência fomentaria um estímulo para que as escolas públicas de má qualidade se prestassem a exercer seus serviços com maior eficácia com a finalidade de manter seus alunos (o que evitaria perda de capital público nessas escolas) e evitar a debandada maciça para a iniciativa privada. De outra ponta, as escolas particulares, entre elas, igualmente competiriam para melhorar ainda mais os seus serviços e atrair os alunos insatisfeitos da rede pública (FRIEDMAN, 1980, p. 171/172), que por sua vez levariam consigo seus vouchers para as escolas privadas, aumentando significativamente suas receitas.

Esses pilares centrais dos vouchers são explicados por Cunha (2008, p. 9) da seguinte forma:

O sistema de voucher, dentro da área de educação, é apontado como sendo uma possibilidade de melhoramento da qualidade de ensino, de aumento da participação e como forma de aumentar a competição entre a escola pública e privada. Sendo este 


\section{INVESTIMENTO PÚBLICO NA EDUCAÇÃO PRIVADA: OS VOUCHERS COMO INSTRUMENTO DE ALCANCE DA QUALIDADE EDUCACIONAL}

sistema nada mais do que a devolução do imposto pago pelo indivíduo que trabalhou na economia formal e que é destinado à educação (construção, expansão e investimentos na rede pública) e devolvido não mais através do investimento direto feito pelo Estado e sim através da distribuição de vouchers, onde [sic] os pais poderão escolher a escola que melhor se adéqua às suas necessidades e pagá-la mesmo que parcialmente através dele.

No Brasil, a qualidade do ensino privado é muito superior ao ensino público, e isso é sentido pela população e provado pelas estatísticas, ao passo que, necessitando o país atingir as metas educacionais com as quais se comprometeu, tais argumentos por certo justificariam uma alteração legislativa autorizativa para que verbas públicas utilizadas para a educação básica, assim com já ocorre no ensino superior, pudessem ser destinadas às Instituições Privadas, buscando sempre a efetivação do direito social da educação estampado no art. $6^{015}$ da Constituição Federal.

O propósito dos vouchres não visa aumentar os investimentos em educação, não obstante sempre serem bem vindos, mas simplesmente teria como foco a destinação do custo médio já pago por aluno na rede pública, redirecionando esse montante para a rede privada, mas somente para aqueles que optassem pela alteração, sendo, portando, exclusivamente de cunho facultativo dos pais ou responsáveis pelos educandos.

Em que pese visar a efetivação de um direito social, não se pode negar que a natureza dos vouchers encaixa-se perfeitamente dentro da ideia do liberalismo moderno, na medida em que mesmo sendo a educação ainda um dever constitucional do Estado, todavia, é prestada concomitantemente através das instituições particulares, o que já se caracteriza como um indicativo de que o Poder Público não tem capacidade de oferecer educação de qualidade, podendo, então, possibilitar à escola particular, melhor capacitada, a prestação desses serviços, assim como ocorreu no Brasil no início da década de 1990 quando se iniciaram diversas transposições de atividades essências, antes prestados pelo Estado, para a iniciativa privada, tendo como um das causas principais o reconhecimento da ineficiência estatal na gerência e manutenção de diversos serviços.

Vislumbrando a possibilidade de escolha dos pais pela melhor escola e tecendo

15 “Art. $6^{\text {o }}$ São direitos sociais a educação, a saúde, a alimentação, o trabalho, a moradia, o transporte, o lazer, a segurança, a previdência social, a proteção à maternidade e à infância, a assistência aos desamparados, na forma desta Constituição.” 
sugestões relevantes para a reforma do ensino básico, Souza e Costa (2009) aduzem que o incremento dos vouchers estaria ligado a uma ideia de privatização do ensino, alegando que essa modalidade poderia ser dada através de vantagens fiscais, dando como exemplo o que já acontece no Programa Universidade para Todos (Prouni), o qual se destina à concessão de bolsas de estudos de 50\% e de $100 \%$ ao ensino superior em instituições privadas para estudantes de baixa renda e que tenham estudado o ensino médio exclusivamente em escolas públicas ou particular, estes com a condição de terem sido bolsistas integrais (PROUNI).

A ideia de Milton Friedman, contudo, encontra resistência, uma vez que seus contestadores se utilizam dos ensinamentos de Ludwig von Mises, alegando que os vouchers dariam ao Estado ainda mais poder de dominação das escolas privadas.

Em capítulo destinado aos fundamentos políticos da paz, von Mises (2010, p. 134), de forma um tanto radical, ressaltando que o contexto desses ensinamentos se dá sob a ótica de escolas europeias e foram escritos após a Primeira Guerra Mundial, traça um paralelo com a educação para avaliar que a interferência do Estado somente traria mais sujeição das minorias em face de um suposto caráter político estatal, segundo o qual as escolas que recebesse investimentos financeiros seriam guiadas por ideologias do poder público, concluindo que instituições privadas de ensino deveriam permanecer afastadas de gerência direta do Estado, cada qual com sua competência.

Esclarecendo os fundamentos de von Mises, Rockweel (2014) aduz que, segundo essa teoria, o dinheiro recebido pelos vouchers passaria a controlar as instituições privadas, colocando-as sob domínio do Estado:

Ao contrário, os vouchers piorarão as coisas. Em vez de aumentar as oportunidades educacionais, os vouchers irão aumentar os tentáculos do governo sobre a educação, aumentar os custos da educação, aumentar a dependência das pessoas em relação ao estado, e aumentar o poder geral do estado.

Dado que o estado sempre acaba controlando aquilo que ele subsidia, as escolas privadas que aceitarem os vouchers estarão sujeitas a todos os tipos de regulamentação estatal. Dado o histórico do estado, é inconcebível que ele opere de outra maneira. As escolas privadas passarão a prestar contas ao estado, e não mais aos pais.

Embora essa linha de pensamento de von Mises defenda argumentos que possibilitariam ao Estado uma maior intervenção na esfera privada, deve-se ressaltar que atualmente isso ocorre em determinada escala, uma vez que as instituições de ensino particulares são obrigadas a cumprir normas gerais de educação nacional, bem como seu funcionamento é precedido de 


\title{
INVESTIMENTO PÚBLICO NA EDUCAÇÃO PRIVADA: OS VOUCHERS COMO INSTRUMENTO DE ALCANCE DA QUALIDADE EDUCACIONAL
}

autorização e avaliação de qualidade pelo próprio Poder Público, tudo em conformidade com o art. 209, I e II, da Carta Magna e art. 7º I e II, da LDB, ou seja, no que é pertinente à educação, o princípio da livre iniciativa, estampado no art. 170, parágrafo único ${ }^{16}$ da Constituição, já é relativizado.

Por evidente que tal proposta só se mostra relevante partindo do pressuposto que o Estado realmente demonstra sinais de mau prestador do serviço educacional, não se podendo olvidar que esse serviço tem natureza pública, de tal forma que, se não prestado a contento, sua efetivação poderá se dar pelo iniciativa dos particulares.

Essa ineficiência na prestação do serviço público e sua transferência para a âmbito privado é observada por Barroso (2002, 127) da seguinte forma:

\begin{abstract}
A constatação de que o Estado não possui recursos para os investimentos necessários e que também é geralmente um mau administrador, conduziu ao processo de transferência da execução de serviços e obras públicas para o setor privado. Mas o fato de determinados serviços públicos serem prestados por empresas privadas concessionárias não modifica sua natureza pública: o Estado conserva suas responsabilidades e deveres em relação a sua prestação adequada. Daí a privatização haver trazido drástica transformação no papel do Estado: em lugar de protagonista dos serviços, suas funções passam a ser as de planejamento, regulamentação e fiscalização das empresas concessionárias.
\end{abstract}

Nessa linha, como alternativa, os vouchers poderiam ser repassados à iniciativa privada através de parcerias público-privadas, criando-se para cada esfera (estadual e municipal) legislações específicas sobre o regramento dessa modalidade.

Em estudo aprofundado sobre a destinação de verbas públicas da educação para a iniciativa privada através de parcerias, Domiciano (2011) traz a análise do programa "bolsa creche” do município de Hortolândia, localizado no Estado de São Paulo, que, na lei municipal 1.506/2005, focando o aumento de ofertas de vagas no ensino infantil, possibilitou a formação de convênio com escolas particulares que receberiam alunos da rede pública que não conseguissem vagas nos estabelecimentos próximos de sua residência. Embora a aludida lei não visasse a concorrência entre as instituições de ensino público e privado, seu objetivo precípuo é dar cumprimento ao dever de prestar a educação conforme designado pela Constituição Federal.

\footnotetext{
16 “Art. 170. A ordem econômica, fundada na valorização do trabalho humano e na livre iniciativa, tem por fim assegurar a todos existência digna, conforme os ditames da justiça social, observados os seguintes princípios: Parágrafo único. É assegurado a todos o livre exercício de qualquer atividade econômica, independentemente de autorização de órgãos públicos, salvo nos casos previstos em lei.”
} 
Outros exemplos concretos da aplicação dos vouchers, além dos Estados Unidos, foram Chile, Colômbia, Índia e Suécia, não cabendo a essa pesquisa avaliar o sucesso ou o fracasso do modelo nesses países, os quais, devido às particularidades de cada nação, alcançaram diferentes resultados.

Inicialmente esses vouchers deveriam ser destinados às famílias mais carentes, posto serem, em tese, as que mais se utilizam da educação de baixa qualidade ofertada pelo sistema público, possibilitando, assim, que podussem ter acesso à mesma qualidade educacional recebida pelos mais favorecidos economicamente na rede privada, alcançando, assim, a efetividade do direito individual da igualdade exposto no art. $5^{\circ}$ da Carta da República. Santos (2003, p. 56) ensina a amplitude desse direito de igualdade:

Temos o direito a ser iguais quando a nossa diferença nos inferioriza; e temos o direito a ser diferentes quando a nossa igualdade nos descaracteriza. Daí a necessidade de uma igualdade que reconheça as diferenças e de uma diferença que não produza, alimente ou reproduza as desigualdades.

Destarte, a proposta dos vouchers é exclusivamente oferecer uma opção de acesso ao ensino de qualidade ministrado por instituições privadas para aqueles que, por suas inferiores condições econômicas, não teriam acesso pelas vias normais, na medida em que teria o Estado a tarefa de remunerar as escolas particulares que oferecessem esse serviço à população mais carente.

Essa busca pela qualidade da educação é flagrante em nossa legislação, como se pode observar ao analisar o art. 206, VII, e art. 209, II, da Constituição, o art. $3^{\circ}$, IX ${ }^{17}$, da LDB e o art. $2^{\circ}, I^{18}$, da Lei 13.005/2014, e por tal razão devem ser o supedâneo principal da busca pela validação dos vouchers.

Entretanto, para a viabilidade dessa transferência de recursos, de pronto se percebem algumas barreira legais, especialmente no tocante ao art. 213 da Constituição Federal e ao art. 77 da LDB, posto que os recursos públicos, como regra, são destinados às escolas públicas, podendo ser dirigidos às escolas comunitárias, confessionais ou filantrópicas, cujas naturezas jurídicas figuram como escolas particulares que não visam a obtenção de lucro. Neste particular,

\footnotetext{
17 “Art. $3^{\circ} \mathrm{O}$ ensino será ministrado com base nos seguintes princípios:

IX - garantia de padrão de qualidade (...)”

18 “Art. 2o São diretrizes do PNE:

IV - melhoria da qualidade da educação (...)”
} 


\section{INVESTIMENTO PÚBLICO NA EDUCAÇÃO PRIVADA: OS VOUCHERS COMO INSTRUMENTO DE ALCANCE DA QUALIDADE EDUCACIONAL}

o maior número de instituições privadas no Brasil são aquelas que buscam lucro em sua atividade, denominadas escolas particulares stricto sensu, conforme classificação trazida pelo art. 20, I, da LDB, e que, de acordo com essa natureza jurídica, não poderiam receber diretamente esses recursos provenientes dos vouchers, devendo, portanto, ainda serem estudadas formas de adaptação legislativa para que essa modalidade de adimplemento fosse amplamente introduzida.

De qualquer modo, a busca pela melhoria da educação não pode ignorar a alternativa da participação da iniciativa privada com vistas à concretização de um ensino de qualidade.

\section{CONSIDERAÇÕES FINAIS}

Conforme se vislumbram nos dados estatísticos, a educação brasileira pública mostra índices inferiores àqueles obtidos pelas instituições privadas, demonstrando evidente superioridade qualitativa das escolas particulares e comprovando a ineficiência e a incapacidade do Estado gerir e ofertar o ensino.

Considerando os números trazidos pelo Pisa e pelo IDEB, é notório que a qualidade do ensino público brasileiro está longe de ser aquela almejada pela Constituição Federal, de tal formar que medidas precisam urgentemente ser tomadas, sendo o voucher uma alternativa que possibilitaria o aumento do índice da qualidade da educação, posto que seriam destinadas verbas públicas para a iniciativa privada, passando as escolas particulares a prestar o serviço educacional desejado.

Essa opção pelas escolas particulares, segundo a teoria de Friedman, além de tirar do Estado a sobrecarga da prestação do serviço, possibilitaria a competição entre as escolas particulares por esses alunos, posto que os pais (ou responsáveis) de famílias mais carentes utilizariam os vouchers para colocar seus filhos em escolas de melhor qualidade, trazendo benefícios também para a rede pública, que, com receio de perder totalmente seus discentes, passariam a implementar melhorias na prestação do serviço educacional.

Desse modo, a opção dos vouchers atingiria o tão buscado padrão de qualidade, bastando, para tanto, alterações legislativas que pudessem autorizar o repasse de verbas públicas para instituições de ensino particulares em sentido estrito, ou seja, aquelas que visam lucro em sua atividade, e não somente para as escolas de natureza filantrópica.

\section{REFERÊNCIAS}


BARROSO, Luís Roberto. Apontamentos Sobre as Agências Reguladoras. In: MORAES, Alexandre de (coord.). Agências Reguladoras. São Paulo: Atlas, 2002.

BRASIL. Constituição (1998) Disponível em: $<$ http://www.planalto.gov.br/ccivil_03/constituicao/constituicao.htm>. Acesso em: 18 dez. de 2017.

. Lei 8.069, de 13 de julho de 1990. Dispõe sobre o Estatuto da Criança e do Adolescente e dá outras providências. Disponível em <https://www.planalto.gov.br/ccivil_03/leis/L8069Compilado.htm> Acesso em 18 dez. 2017.

. Lei $n^{0}$ 9394, de 20 de dezembro de 1996. Lei de diretrizes e bases da educação nacional. Disponível em: <http://www.planalto.gov.br/ccivil_03/leis/L9394.htm>. Acesso em: 12 jan. 2018.

. Lei 13.005, de 25 de junho de 2014. Aprova o Plano Nacional de Educação - PNE e dá outras providências. Disponível em <http://www.planalto.gov.br/CCIVIL_03/_Ato20112014/2014/Lei/L13005.htm>. Acesso em 18 dez. de 2017.

BRASIL. Instituto Nacional de Estudos e Pesquisas Educacionais Anísio Teixeira (INEP). Brasil no PISA 2015: Análises e reflexões sobre o desempenho dos estudantes brasileiros. nov. 2016. Disponível em <http://download.inep.gov.br/acoes_internacionais/pisa/resultados/2015/pisa2015_completo_f inal_baixa.pdf>. Acesso em 18 dez. 2017.

Instituto Nacional de Estudos e Pesquisas Educacionais Anísio Teixeira (INEP). Censo Escolar da Educação Básica 2016: notas estatísticas. fev 2017. Disponível em $<$ http://download.inep.gov.br/educacao_basica/censo_escolar/notas_estatisticas/2017/notas_es tatisticas_censo_escolar_da_educacao_basica_2016.pdf>. Acesso em $18 \mathrm{dez} .2017$.

Instituto Nacional de Estudos e Pesquisas Educacionais Anísio Teixeira (INEP). Resumo técnico: resultados do índice de desenvolvimento da educação básica - IDEB 20052015. 2015. Disponível em <http://download.inep.gov.br/educacao_basica/portal_ideb/planilhas_para_download/2015/res umo_tecnico_ideb_2005-2015.pdf>. Acesso em dez. 2017

Ministério da Educação (MEC). Planejando a próxima década: conhecendo as 20 metas do plano nacional de educação. 2014. Disponível em $<$ http://pne.mec.gov.br/images/pdf/pne_conhecendo_20_metas.pdf > Acesso em 18 dez. 2017

. Ministério da Educação (MEC). Programa universidade para todos (PROUNI). Disponível em < http://prouniportal.mec.gov.br/index.php>. Acesso em 18 dez. 2017.

CUNHA, Rina Nogueira D. da.. Aplicação de vouchers para incentivo a educação no Brasil. 58 f. Dissertação (Mestrado em Finanças e Economia Empresarial) - Fundação Getúlio Vargas - FGV, Rio de Janeiro, 2008, Disponível em < http://bibliotecadigital.fgv.br/dspace/handle/10438/7906>. Acesso em 02 jan. 2018.

DOMICIANO, Cássia Alessandra. A educação infantil via programa bolsa creche: o caso do 
município paulista de Hortolândia. Educ. rev., Belo Horizonte , v. 27,n. 3, p. 231-250, dez. 2011.Disponível em < http://www.scielo.br/scielo.php?script=sci_arttext\&pid=S0102$46982011000300012 \& \operatorname{lng}=$ pt\&nrm=iso $>$. Acesso em 02 jan. 2018.

FRIEDMAN, Milton. FRIEDMAN, Rose D. Capitalismo e liberdade. Tradução Afonso Celso da Cunha Serra Rio de Janeiro. LTC. 2014. recurso online. ISBN 978-55-216-2709-8 .

1980.

. Liberdade de Escolher. Tradução de Ruy Jugmann, 2 ed. Rio de Janeiro. Record.

HORTOLÂNDIA (SP). LEI 1.506/2005. AUTORIZA O MUNICÍPIO DE HORTOLÂNDIA A FIRMAR CONVÊNIO COM ENTIDADES FILANTRÓPICAS E ESCOLAS PARTICULARES DE EDUCAÇÃO INFANTIL, OBJETIVANDO O AUMENTO DE OFERTA DE VAGAS, COM A CONCESSÃO DE "BOLSAS CRECHE" ÀS CRIANÇAS QUE NÃO OBTENHAM VAGAS NA REDE MUNICIPAL E DÁ OUTRAS PROVIDÊNCIAS. DISPONÍVEL EM <HTTPS://LEISMUNICIPAIS.COM.BR/SP/HORTOLANDIA/LEI-1506-2005HORTOLANDIA-SP.PDFF> ACESSO EM 18 DEZ. DE 2017.

PIOVESAN, Flávia. Direitos humanos e do direito constitucional internacional. 14 ed., rev. e atual. São Paulo, Saraiva, 2013.

ROCKWELL, Lew. Vouchers escolares: o caminho mais “eficiente para a socialização da educação”, set. 2015. Disponível em < https://www.mises.org.br/Article.aspx?id=1942>. Acesso em 02 jan. 2018.

SANTOS, Boaventura de Souza. Reconhecer para libertar: os caminhos do cosmopolitanismo multicultural. Rio de Janeiro: Civilização Brasileira, 2003.

SOUZA, Alberto de Mello e; COSTA, Marly de Abreu. Reformas do ensino básico: tendências e limites. Revista Ensaio: Avaliação e Políticas Públicas em Educação, [S.l.], v. 17, n. 64, p. 477-494, jul. 2009. ISSN 1809-4465. Disponível em:

$<$ http://revistas.cesgranrio.org.br/index.php/ensaio/article/view/654>. Acesso em: 02 jan. 2018.

VON MISES, Ludwig. Liberalismo: segundo a tradição clássica. Tradução de Haydn Coutinho Pimenta, 2 ed. Rio de Janeiro, Instituto Liberal, 1987. 